\title{
Study of the sexual and reproductive health of young women with visual impairment
}

\author{
Prajakta Ganesh Joshi ${ }^{1 *}$, Ganesh Arun Joshi
}

\begin{abstract}
${ }^{1}$ Department of Obstetrics and Gynecology, LN Medical College and Research Centre, Bhopal, Madhya Pradesh, India ${ }^{2}$ Department of Physical Medicine and Rehabilitation, CRC, Bhopal, Madhya Pradesh, India
\end{abstract}

Received: 12 September 2019

Accepted: 25 October 2019

\author{
*Correspondence: \\ Dr. Prajakta Ganesh Joshi, \\ E-mail: pjosh92@gmail.com
}

Copyright: (c) the author(s), publisher and licensee Medip Academy. This is an open-access article distributed under the terms of the Creative Commons Attribution Non-Commercial License, which permits unrestricted non-commercial use, distribution, and reproduction in any medium, provided the original work is properly cited.

\begin{abstract}
Background: Census figures in 2011 have depicted that half of the visually impaired in India are women and a third of these females are in reproductive age group. This study was undertaken to identify the gynaecological health problems of the visually impaired young women and impart them necessary health education.

Methods: All young visually impaired women attending composite regional centre for persons with disabilities, Bhopal during one day were offered consultation by gynecologist. Their needs and clinical findings were recorded.

Results: There were 15 young women in the age range of 19 to 27 years participating in the study. This was their first ever visit to gynecologist. More than half of them reported that menstrual hygiene was taught to them by their mother, a third by peers, and one participant each reported that sister, aunt, and teacher helped them learn it. The cramping pain and warmth of discharge per vaginum helped them identify the onset of menses. Primary dysmenorrhea was the commonest complaint for which they relied on rest and over the counter available medicine.

Conclusions: This study highlights the need of the inclusion of the visually impaired girls in adolescent reproductive and sexual health education with appropriate teaching learning material. Access to a gynecologist for the visually impaired shall be ensured through camps on regular basis and referral on individual need basis.
\end{abstract}

Keywords: Blindness, Gynecology, Low vision, Sex education, Visually impaired persons, Women's health

\section{INTRODUCTION}

Bourne et al, estimated in a systematic review that there are 36 million blind people in the world and 217 million people with low vision. The trends of blindness are reducing in percentage, but the actual numbers are rising due to population growth. Out of the visually impaired population $56 \%$ are women. ${ }^{1}$ Almost $90 \%$ of these are in low- and middle-income countries where intervention may reduce the disability. The Census of India, 2011 states that out of 26.8 million persons with disabilities, one fifth have visual impairment. ${ }^{2}$ Out of these, half are females and a third of these females in reproductive age. World Health Organization has stated in its fact sheet that
$80 \%$ of blindness is avoidable i.e. can be prevented or treated by use of refractive correction, surgeries, drugs, assistive devices and training in orientation and mobility. ${ }^{3}$

Rehabilitation of persons with visual impairment includes training in independent living skills (ILS) as essential portion taught by orientation and mobility instructor. Use of assistive devices like Braille, optical and non-optical devices for day to day life is also taught. Where general hygiene is routinely taught, sexual and reproductive healthcare shall also be essential.

The women's health issues take a backseat due to social stigma. Harrison et al, have analysed the barriers in 
accessing health information for the visually impaired women along with attitudes of the healthcare staff in a qualitative study. ${ }^{4}$ The persons with visual impairment are rarely seen in healthcare establishments for preventive or curative healthcare. Absence of women with visual impairment in gynaecological clinics raised curiosity about their access to reproductive and sexual health. The opportunity to learn healthy practices is affected by various factors like loss of vision, social stigma, illiteracy, deficit of women empowerment etc. Hence this study was undertaken to identify and treat gynaecological health problems of visually impaired young women and impart necessary health education.

\section{METHODS}

The objective of this study was to describe knowledge and access to healthcare for women with visual impairment. This descriptive study involving visually impaired young women staying in hostel for the visually impaired. The study was carried out at composite regional centre for persons with disabilities, Bhopal on 3rd March 2014. Inclusion criteria for the study were women with certified disability as low vision or blindness who registered for rehabilitation services at the centre. Exclusion criteria were women with normal vision or those who did not consent for participating in the study. Following the ethical principles of World Medical Association Declaration of Helsinki, the participants were included after due informed consent. The second author did the disability evaluation and categorization based on the history, examination and valid disability certificate. The participants were categorized accordingly into Blind and low vision. Blindness is defined as visual acuity less than $3 / 60$ or visual field less than 10 degree in the better eye. Low vision is defined as visual acuity less than $6 / 18$ or visual field less than 40 degree in better eye. The participants were provided counselling, guidance, mobility training, and assistive devices like Braille watch, teaching learning material. Then the first author obtained detailed gynaecological history and examination. According to the gynaecological problems, the appropriate prescription was given along with consultation. This expert gynaecological advice was welcomed by the participants and they came forward with all related queries in healthcare. Then the menstrual hygiene habits and access to gynaecologist was assessed on a questionnaire. Questions on knowledge of preventive healthcare pertinent to gynaecology were asked. The social support system was evaluated that ensured the fundamental women's health care for the visually impaired participants. The findings were recorded in master chart and then presented in results. No statistical analysis was intended.

\section{RESULTS}

There were 15 young women in the age range of 19 to 27 years who participated in the study. The average age of participants was 23 years. They all were doing their graduation and had valid disability certificates. Sixty percent were certified as blind and $40 \%$ with low vision. Twenty percent were from the rural background and $80 \%$ from urban background. They all were unmarried and single. Forty percent had acquired cause of visual impairment and $60 \%$ were having congenital visual impairment. The diagnoses are listed in Table 1.

Table 1: Cause of visual loss.

\begin{tabular}{|lll|}
\hline Sr. No. & Diagnosis & No \\
\hline 1. & Anophthalmos & 3 \\
\hline 2. & Trachoma & 2 \\
\hline 3. & Eruptive fever & 2 \\
\hline 4. & Corneal opacity & 1 \\
\hline 5. & Keratoconus & 1 \\
\hline 6. & Coloboma & 1 \\
\hline 7. & Retinitis pigmentosa & 1 \\
\hline 8. & Retinopathy of prematurity & 1 \\
\hline 9. & Unknown & 3 \\
\hline
\end{tabular}

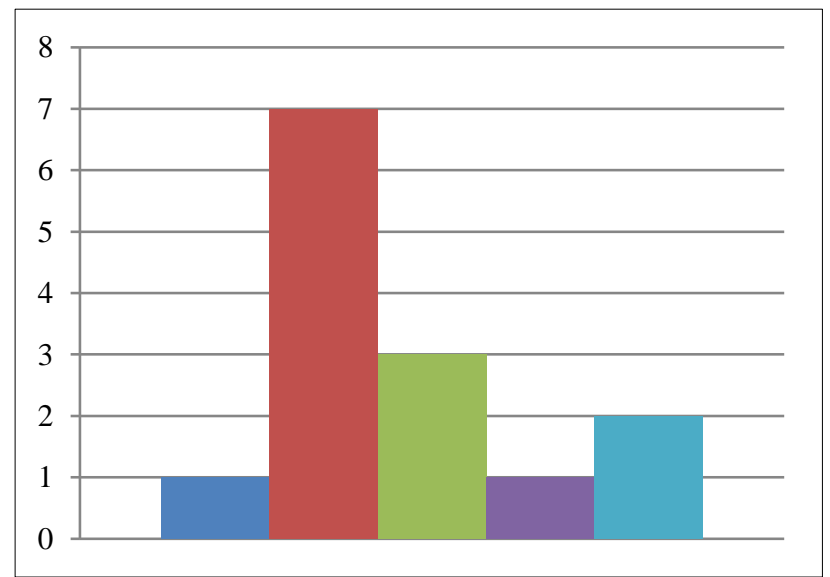

Figure 1: Reported age of menarche - No. on vertical axis and age 12-16 years from left to right.

One of them had locomotor disability due to poliomyelitis while others did not have any additional disabilities. One of the participants had hypothyroidism and was on supplemental therapy for the same. One of them gave history of surgery for ovarian tumour with ascitis. The modal age of menarche was 13 years and the distribution of age of menarche of all participants is given in Figure 1. The menstrual cycles were regular in all except one participant. The menstrual bleeding ranged from 2 to 5 days and cycle duration from 26 to 35 days. The menstrual flow was average in all participants. All were independent in taking care of their menstrual hygiene. More than half of them reported that menstrual hygiene was taught to them by their mother and almost a third by their friends. Others reported that their sister, aunt, teacher helped them learn menstrual hygiene. None of them complained of discharge per vaginum or urinary burning or increased urinary frequency. Primary spasmodic dysmenorrhea was reported by $80 \%$ of the participants. 


\section{DISCUSSION}

This study of women with visual impairment brings forth that they do not have access to essential healthcare by gynaecologist. Zacharias and Wurtman stated in their study that menarche is earlier in visually impaired girls. ${ }^{5}$ Our study found that age of menarche did not differ from general Indian population as surveyed by Sharma. ${ }^{6}$ This difference may be due to small sample in this study. This study indicates that despite being highly educated, the women are unmarried and single. Visual disability has impact on marriage and relationships. In our study, large number of the participants reported suffering from primary dysmenorrhea that was treated by over the counter available medicine and rest. Hot water bottle is another therapy for dysmenorrhea but has its own logistic problem of handling for the blind. The cramping abdominal pain and feeling of warm discharge per vaginum were indicators for the onset of menses for most of the participants. They used month and date pattern for anticipating the cycles, however tactile calendars and indicators were not known to them. Nobody had complaints suggestive of urinary or reproductive tract infections. This was their first ever visit to a gynaecologist. The participants were counselled about contraception, marriage, reproductive health and regular healthcare visits. Goyal, has analysed in personal narrative that overprotection and authoritativeness exerted by parents and institutions affects access of visually impaired girls to sex education. ${ }^{7}$ Our study found that half of the participants learnt about menstrual hygiene from their mother while one third from their peers. We noted that only one participant reported learning about menstrual hygiene from her teacher. Parents who use vision may not be able to anticipate and impart training on this aspect. Learning skills for menstrual hygiene in a similar manner from the visually impaired peer group is an advantage while disadvantage is that the visually impaired peers themselves have insufficient knowledge of sex and reproductive health. Only one of the participants was taught by her teacher. This indicates that special teaching material including tactile models and proper teaching aids in these aspects of adulthood might be lacking. Saulo et al, reported discrimination in reaching out to the visually impaired with information on AIDS. They had to rely on use of barrier safety devices by the other partner. Although aware of HIV AIDS, the access to counselling was restricted for the blind. ${ }^{8}$ In our study we found that the participants were aware of modes of prevention of sexually transmitted diseases. Recently the Rehabilitation Council of India has made it mandatory to share information on HIV AIDS prevention during trainings to the rehabilitation manpower viz. Orientation and mobility instructor, and special teacher. This is a welcome step but generating the confidence, care, rapport and mentorship between the trainers and trainees for complete hygiene and healthcare is required.

\section{CONCLUSION}

This study concludes that the women with visual impairment are not sufficiently trained about menstrual hygiene, reproductive health, contraception and prevention of reproductive tract infections. They need skilled teachers in whom they can confide and get training with appropriately designed tactile kits for the training. They need access to a gynaecologist on regular intervals to address their health issues. The curricula in institutions for the visually impaired shall include sexual and reproductive hygiene in adult independent living. Organizing camps for women with visual disability once or twice in a year is recommended to ensure specialist gynaecologist services.

\section{Recommendations}

There is a need to integrate visually impaired girls under the adolescent reproductive and sexual health program so that they can be imparted training regarding menstrual hygiene, sexually transmitted infections and contraception.

\section{ACKNOWLEDGMENTS}

Authors would like to heartfelt thanks to the participants for their contribution in this study. CRC-Bhopal under the Director, AYJNISHD-Mumbai is acknowledged for providing support for this study.

Funding: No funding sources

Conflict of interest: None declared

Ethical approval: The study was approved by the Institutional Ethics Committee

\section{REFERENCES}

1. Bourne RR, Flaxman SR, Braithwaite T, Cicinelli MV, Das A, Jonas JB, et al. Magnitude, temporal trends, and projections of the global prevalence of blindness and distance and near vision impairment: a systematic review and meta-analysis. The Lancet Global Health. 2017;5(9):e888-97.

2. Disabled persons in India a statistical profile. New Delhi, Social Statistics Division, Ministry of Statistics and Program Implementation, Government of India, 2016. Available at: http://mospi.nic.in/sites/default/files/publication_rep orts/Disabled_persons_in_India_2016.pdf. Accessed on $13^{\text {th }}$ May 2019.

3. Blindness and vision impairment. Key facts, 2018. Available at: https://www.who.int/news-room/factsheets/detail/blindness-and-visual-impairment.

4. Harrison TC, Mackert M, Watkins C. A qualitative analysis of health literacy issues among women with visual impairments. Res Gerontol Nurs. 2010;3(1):49-60.

5. Zacharias L, Wurtman RJ. Blindness: its relation to age of menarche. Sci. 1964;144(11):54-5. 
6. Sharma K. Age at menarche in North West Indian females and a review of Indian data. Ann Human Bio. 1990;17(2):159-62.

7. Goyal N. Denial of sexual rights: insights from lives of women with visual impairment in India. Repro Health Matters. 2017;25(50):138-46.

8. Saulo B, Walakira E, Darj E. Access to healthcare for disabled persons. How are blind people reached by HIV services? Sex Reprod Healthc. 2012;3(1):4953.

Cite this article as: Joshi PG, Joshi GA. Study of the sexual and reproductive health of young women with visual impairment. Int J Reprod Contracept Obstet Gynecol 2019;8:4926-9. 